\title{
Is semen a useful diagnostic tool for rare infections of the central nervous system?
}

\author{
Ruqaiyyah Siddiqui and Naveed Ahmed Khan ${ }^{*}$
}

\begin{abstract}
Given that the blood-testis barrier is more permeable than the blood-brain barrier, the use of semen to detect rare parasitic antigens/infections of the CNS in males is hypothesized.
\end{abstract}

Infections of the central nervous system (CNS) can progress rapidly and cause substantial damage or even death if they are not diagnosed promptly and treated aggressively. Given the involvement of the CNS, it is typical to use cerebrospinal fluid for the identification of infectious agents/antigens, and the host factors to suspected disease. In general, pathogens colonize mucosal surfaces, followed by invasion of the intravascular space leading to haematogenous spread and entry into the CNS at the sites of the blood-brain barrier (BBB) or bloodcerebrospinal fluid (CSF) barrier at the choroid plexus. The use of CSF specimens has been of tremendous value in the diagnosis of CNS infections but the rarity of pathogens/antigens in the CSF in some of the parasitic infections such as neurocysticercosis, cerebral toxoplasmosis, granulomatous amoebic encephalitis due to Acanthamoeba and Balamuthia mandrillaris and primary amoebic meningoencephalitis due to Naegleria fowleri has made accurate diagnosis challenging [1,2]. For such infections, the CSF specimen is generally condensed by centrifugation, followed by microscopic observation for parasites or immunodiagnosis. While there are many similarities between the endothelial cells of the testis and the brain, several lines of evidence suggest that the blood-testis barrier (BTB) exhibits a higher degree of permeability compared with the BBB [3-5]. Physiological experiments have shown that tracers like L-glucose, sucrose, and albumin that do not ordinarily cross the $\mathrm{BBB}$, are readily detected in the lymphatics draining the testis [3]. The BBB is

\footnotetext{
* Correspondence: naveed5438@gmail.com

Department of Biological and Biomedical Sciences, Aga Khan University, Stadium Road, Karachi, Pakistan
}

tightly regulated by the presence of tight junctions between endothelial cells of microvessels, while the BTB is restrictive due to the adjacent Sertoli cells near the basement membrane of the seminiferous tubules. Based on these findings, it is plausible that parasites/antigens cross the semipermeable testicular blood vessels readily, in addition to the highly selective BBB. Given the condensed nature of semen specimens (unlike urine which may be useful to diagnose overwhelming bacterial infections), here we hypothesize the use of semen to detect rare parasitic infections of the CNS, perhaps at a higher density than the CSF. If the results correlate with the CSF findings and the neuroimaging data, it could provide a useful tool in the diagnosis of rare parasitic CNS infections in males. Although our theory to use semen to detect rare parasitic infections of the CNS has a scientific basis, intensive future research is needed to test this theoretical hypothesis before it is widely accepted by the scientific community.

\section{Competing interests}

The authors declare that they have no competing interests.

\section{Authors' contributions}

Both authors contributed equally to this manuscript and both read and approved its final version.

Received: 31 October 2012 Accepted: 13 December 2012 Published: 19 December 2012

\section{References}

1. Martinez AJ, Visvesvara GS: Free-living, amphizoic and opportunistic amebas. Brain Pathol 1997, 7:583-98.

2. White AC Jr: New developments in the management of neurocysticercosis. J Infect Dis 2009, 199:1261-2. 
3. Setchell BP, Breed WG: Anatomy, vasculature, and innervation of the male reproductive tract. In Physiology of Reproduction. 3rd edition. Edited by Neill JD. New York: Elsevier Press; 2006:771-825.

4. Kormano M: Penetration of intravenous trypan blue into the rat testis and epididymis. Acta Histochem 1968, 30:133-136.

5. Setchell BP, Pollanen P, Zupp JL: Development of the blood-testis barrier and changes in vascular permeability at puberty in rats. Int J Androl 1988, 11:225-33.

doi:10.1186/1756-3305-5-297

Cite this article as: Siddiqui and Khan: Is semen a useful diagnostic tool for rare infections of the central nervous system? Parasites \& Vectors 2012 5:297.

\section{Submit your next manuscript to BioMed Central and take full advantage of:}

- Convenient online submission

- Thorough peer review

- No space constraints or color figure charges

- Immediate publication on acceptance

- Inclusion in PubMed, CAS, Scopus and Google Scholar

- Research which is freely available for redistribution 